Document downloaded from:

http://hdl.handle.net/10251/65522

This paper must be cited as:

Ballesteros Pascual, L.; Ortiz Moragón, J.; Gallardo Bermell, S.; Martorell Alsina, SS. (2015). An overview of measurements of radionuclides in foods of the Comunidad Valenciana (Spain). Radiation Physics and Chemistry. 116:111-115.

doi:10.1016/j.radphyschem.2015.05.022.

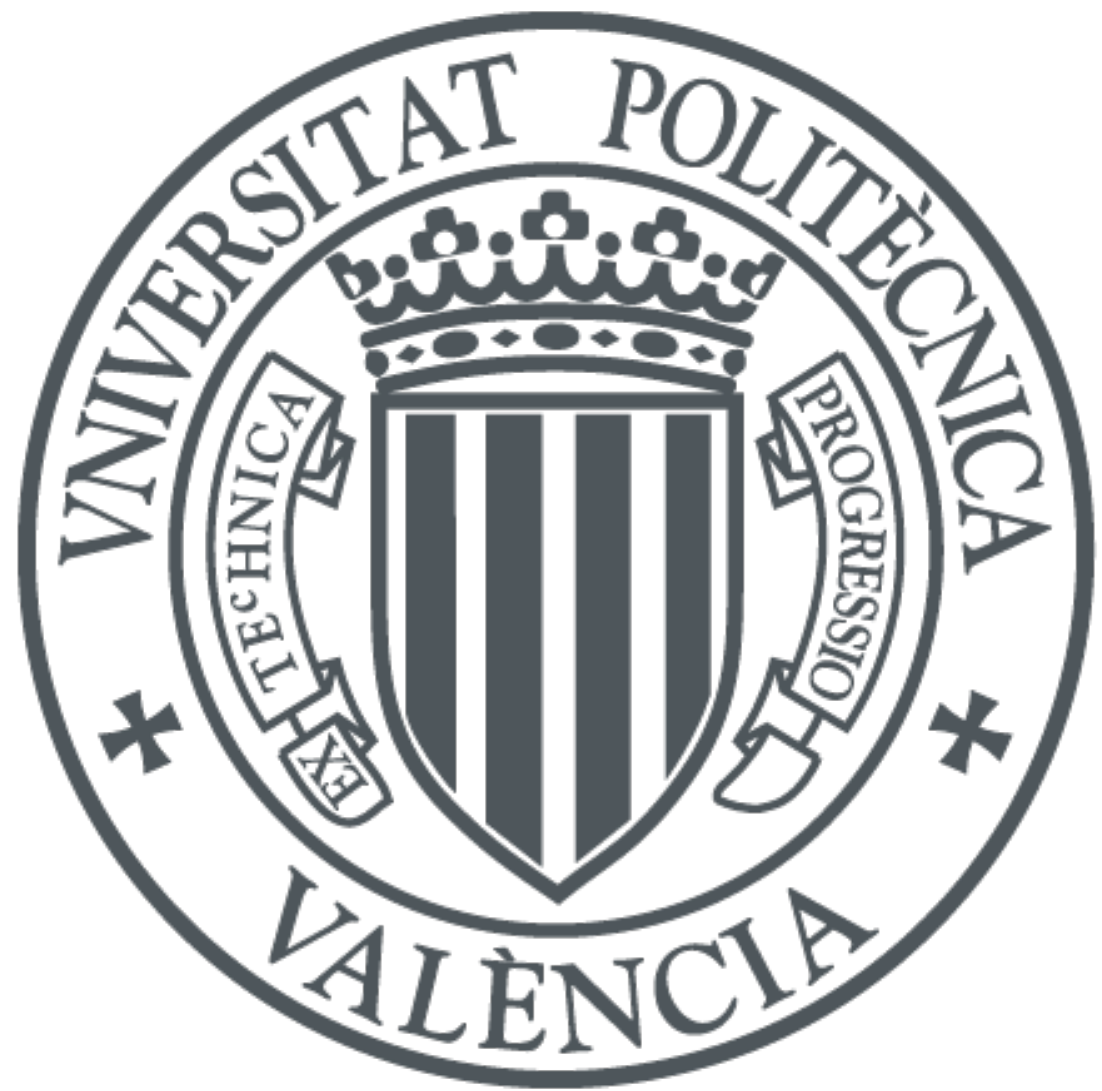

The final publication is available at

http://dx.doi.org/10.1016/j.radphyschem.2015.05.022

Copyright Elsevier

Additional Information 


\title{
An overview of measurements of radionuclides in foods of the Comunidad Valenciana (Spain)
} $\underline{\text { L. Ballesteros }}^{*}, 1$, J. Ortiz ${ }^{1}$, S. Gallardo ${ }^{2}$, S. Martorell ${ }^{1,3}$

${ }^{1}$ Laboratorio de Radiactividad Ambiental, Universitat Politècnica de València, Valencia, Spain

${ }^{2}$ Instituto de Seguridad Industrial, Radiofísica y Medioambiental, Universitat Politècnica de València, Valencia, Spain

${ }^{3}$ Departamento de Ingeniería Química y Nuclear, Universitat Politècnica de València, Valencia, Spain

*Corresponding author. lballest@upvnet.upv.es

\begin{abstract}
Environmental radioactivity monitoring includes the determination of radionuclides in foods since they are an important way of intake of radionuclides to the human organism. Moreover, knowledge of the levels of radionuclides in foodstuffs will inform about the environmental radioactivity background permitting to control possible contamination due to human activity, such as agriculture activity, nuclear power plants or other radioactive facilities.

The Environmental Radioactivity Laboratory (LRA) at the Universitat Politècnica de València (UPV) performs measurements on representative foods from all over the Comunidad Valenciana (CV). Those measurements are part of several monitoring programs promoted by the Generalitat Valenciana.

A total of 2200 samples of fruits, cereals, vegetables, milk, meat, eggs and fish coming from markets, agricultural cooperatives or small producers have been analysed.

A gamma-ray spectrometry analysis has been performed in all samples. It has been detected ${ }^{40} \mathrm{~K}$ in all samples, ${ }^{7} \mathrm{Be}$ in some of them. Radiochemical separation of ${ }^{90} \mathrm{Sr}$ has been carried out in some of the samples collected, mainly orange and lettuce.

Samples of lettuce and chard collected following Fukushima Nuclear Power Plant (NPP) accident present activity concentration of ${ }^{131} \mathrm{I}\left(0.10\right.$ to $\left.1.51 \mathrm{~Bq} \cdot \mathrm{kg}^{-1}\right)$.

In this paper, a review of the data obtained at the 1991-2013 period in the framework of the development of the Environmental monitoring program is presented.
\end{abstract}

Keywords: environmental monitoring, radionuclides, food.

\section{Introduction}

Chernobyl and more recently Fukushima nuclear accidents have confirmed that not only the area next to the nuclear facility but also areas which are far away from the nuclear plant are exposed to an increment of levels of radioactivity above the background level (Thakur, P., 2013, Huang-Sheng Chiu, et al., 2013, Beresford, N.A., et al., 2012). In addition, human activities such as industry and agriculture may also increase background level in surrounding areas. Consequently, there has been a growing interest in measuring the levels of radioactivity of both natural and induced by human activity on the environment and therefore their potential effect in humans (Abukawa J., et al, 1998, Akhter, P., et al, 2003, Arogunjo, A.M., et al.,2005, Bolca, M., et al, 2007, Choi, M-S., et al. 2008, Esposito M., et al., 2002, Froidevaux, P., et al, 2004, IAEA,1989, Mahiban Ross, E., et al, 2013, Shanthi, G., et al, 2010).

The natural isotopes of radioactive chains $\left({ }^{232} \mathrm{Th}\right.$ and $\left.{ }^{238} \mathrm{U}\right)$ and ${ }^{40} \mathrm{~K}$ in the earth's crust, which can also be enhanced due to human activities, and artificial isotopes present in the environment can be all of them incorporated into human through the food chain. Hence, the importance and desirability of measuring the levels in food.

Table 1 shows the maximum permitted levels for foodstuffs set by the European Commission because of the Chernobyl accident (Euratom, 1987a, 1989b) 
Table 1. Maximum permitted levels for foodstuffs $\left(\mathrm{Bq} \cdot \mathrm{kg}^{-1}\right)$

(based on COUNCIL REGULATION (EURATOM) No 3954/87, updated in 1989 (No 2218/89)

\begin{tabular}{|c|c|c|c|c|}
\hline Radionuclide & $\begin{array}{l}\text { Baby } \\
\text { foods }\end{array}$ & $\begin{array}{l}\text { Dairy } \\
\text { produce }\end{array}$ & $\begin{array}{l}\text { Other } \\
\text { foodstuffs }\end{array}$ & $\begin{array}{l}\text { Liquid } \\
\text { foodstuffs }\end{array}$ \\
\hline${ }^{90} \mathrm{Sr}$ & 75 & 125 & 750 & 125 \\
\hline${ }^{131} \mathrm{I}$ & 150 & 500 & 2000 & 500 \\
\hline${ }^{239} \mathrm{Pu} \mathrm{\&}{ }^{241} \mathrm{Am}$ & 1 & 20 & 80 & 20 \\
\hline${ }^{134} \mathrm{Cs} \mathrm{\&}{ }^{137} \mathrm{Cs}$ & 400 & 1000 & 1250 & 1000 \\
\hline
\end{tabular}

Since the late 80's, the Environmental Radioactivity Laboratory (LRA) at the Universitat Politècnica de València (UPV) has performed the measurement of radioactivity in representative foods from all over the Comunidad Valenciana $(\mathrm{CV})$ in the framework of several monitoring programs promoted by the Generalitat Valenciana.

One of the main purposes of such environmental monitoring programs has been to obtain data to establish confident background values of radioactivity levels that allow to detect possible variations due to human activity and, therefore, to assess the radiation exposure to the public if necessary.

Gamma-ray spectrometry analysis has been performed in all samples in order to assess the natural isotope series of ${ }^{238} \mathrm{U}\left({ }^{214} \mathrm{~Pb},{ }^{214} \mathrm{Bi}\right)$ and ${ }^{232} \mathrm{Th}\left({ }^{210} \mathrm{Tl},{ }^{212} \mathrm{~Pb}\right),{ }^{7} \mathrm{Be}$ and ${ }^{40} \mathrm{~K}$ and the anthropogenic isotopes that result from fission and activation products (such as ${ }^{137} \mathrm{Cs},{ }^{134} \mathrm{Cs},{ }^{131} \mathrm{I},{ }^{65} \mathrm{Zn}$, ${ }^{60} \mathrm{Co}$, etc). In addition, the radiochemical separation of ${ }^{90} \mathrm{Sr}$ has been performed in some of the collected samples due to the importance of this isotope, which would be readily assimilated by the human body due to its nature, (ICRP, 1973).

In this paper the results of gamma-ray spectrometry analysis and the determination of ${ }^{90} \mathrm{Sr}$ in representative foods of the CV are presented.

\section{Materials and methods}

\subsection{Sample collection}

During the period 1991-2013, 2200 samples of fruits, cereals and vegetables representatives of different production areas of the CV were collected. The samples were supplied by agricultural cooperatives and small producers or purchased in markets (UNE, 1981). Most of the samples collected every year correspond to lettuces and oranges as they are two types of crop produced throughout the CV and are harvested during most of the year. In addition, lettuce is a broadleaf plant whose edible portion is exposed directly to the environment and orange is a very important foodstuff in $\mathrm{CV}$ at both consumption and export. Moreover, samples such as fruits, grains and vegetables and milk, meat, eggs and fish were collected at points near the NPP of Cofrentes (Valencia). Figure 1 shows the map of CV. Sampling locations are indicated. 


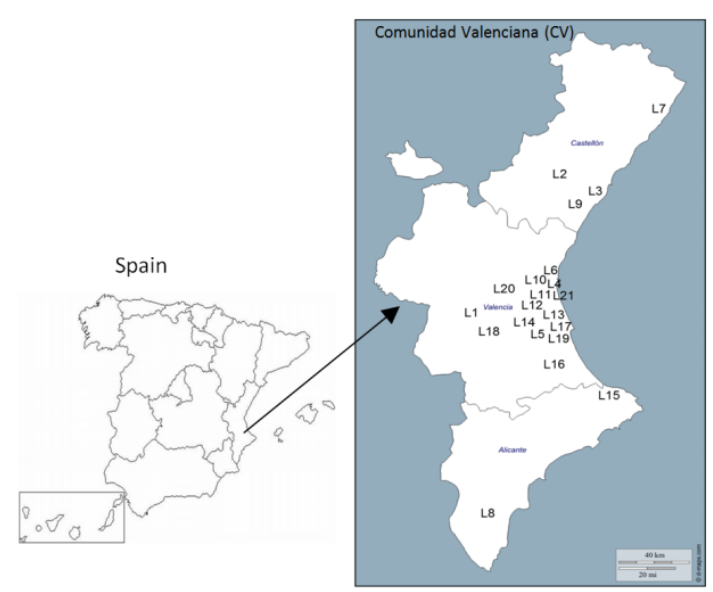

Figure 1. Location of sampling points.

\subsection{Gamma-ray spectrometry analysis}

After removing the inedible part, samples were oven dried at $110^{\circ} \mathrm{C}$ to constant weight and only some samples as almonds and olives were ashed at $400{ }^{\circ} \mathrm{C} .{ }^{131} \mathrm{I}$ was not quantified in ashed samples. Then samples were milled, sieved at $500 \mu \mathrm{m}$ and homogenized. Samples were placed in an appropriate beaker to gamma measurement.

The gamma-ray spectrometry analysis was performed using a germanium detector n-type HPGe (ORTEC) with a relative efficiency of $18 \%$ and a resolution of $1.88 \mathrm{keV}$ at $1332 \mathrm{keV}\left({ }^{60} \mathrm{Co}\right)$. Activities were determined through the following photon emission: $661.65 \mathrm{keV}$ for $137 \mathrm{Cs}, 1460.75$ $\mathrm{keV}$ for ${ }^{40} \mathrm{~K}, 364.48 \mathrm{keV}$ for ${ }^{131} \mathrm{I}, 351.92$ for ${ }^{214} \mathrm{~Pb}, 609.31$ for ${ }^{214} \mathrm{Bi}$ and $477.59 \mathrm{keV}$ for ${ }^{7} \mathrm{Be}$. Efficiency calibration was performed from $55 \mathrm{keV}$ to $1800 \mathrm{keV}$ using a reference standard solution (QCY48, Amersham). Samples were measured during 60000 s. The method was validated according to the ISO 17025 standard protocol requirements.

\subsection{Radiochemical analysis of ${ }^{90} \mathrm{Sr}$}

The determination of radiostrontium was carried out following the method proposed by U.S. EPA (U.S., 1984). Ashed sample is dissolved in hydrochloric acid and strontium carrier is added. Magnesium is precipitated and the sample is passed through a cation exchange resin (DOWEX 50W-X8, 50-100 mesh), which retains the barium and strontium. Strontium is selectively eluted and precipitated as carbonate. The precipitate was placed in a stainless-steel planchet and measured during $1000 \mathrm{~min}$ in a low background proportional counter (BERTHOLD LB 770-2). Efficiency calibration was performed using a reference solution of ${ }^{90} \mathrm{Sr} /{ }^{90} \mathrm{Y}$ (SIZ24, Amersham). The measured efficiency was $35 \%$ and the lowest MDA values (Minimum Detected Activity) obtained was $10 \mathrm{mBq} \cdot \mathrm{kg}^{-1}$. Samples were measured during $1000 \mathrm{~min}$. The method was validated according to the ISO 17025 standard protocol requirements.

\section{Results and discussion}

\subsection{Gamma-ray emitting radioisotopes}

About 2200 samples were collected throughout the CV. Gamma-ray spectrometry analysis shows the presence of ${ }^{40} \mathrm{~K}$ in all samples. ${ }^{7} \mathrm{Be}$ was detected in samples of vegetables such as chard, cabbage and lettuce with large surface of deposition, in fruits such as grapes and apricots that consumed unpeeled and in samples of unhusked cereals. Values range from 0.5 to $56 \mathrm{~Bq} \cdot \mathrm{kg}^{-1}$. 
In some samples, ${ }^{214} \mathrm{~Pb}$ and ${ }^{214} \mathrm{Bi}$ were detected with values close to MDA values $(0.25$ and 0.30 Bq. $\mathrm{kg}^{-1}$, respectively). It has also been detected ${ }^{131} \mathrm{I}$ in samples collected following the Fukushima NPP accident. ${ }^{137} \mathrm{Cs}$ activity is lower than the detection limit of $0.08 \mathrm{~Bq} \cdot \mathrm{kg}^{-1}$ in all samples collected.

\subsubsection{Activity concentration of ${ }^{40} \mathrm{~K}$}

Table 2 shows the values of ${ }^{40} \mathrm{~K}$ activity concentration for the different types of samples analyzed. Total number of samples (n), the average value of activity (A), the standard deviation (s) and the range of values are listed. The results agree with literature data (Arogunjo, A.M., et al.,2005, Bolca, M., et al, 2007, Choi, M-S., et al. 2008, Esposito M., et al., 2002, Froidevaux, P., et al, 2004, Mahiban Ross, E., et al, 2013, Shanthi, G., et al, 2010).

Table 2. Activity concentration of ${ }^{40} \mathrm{~K}\left(\mathrm{~Bq} \cdot \mathrm{kg}^{-1}\right)$ in foodstuffs.

\begin{tabular}{|c|c|c|c|c|c|}
\hline $\begin{array}{c}\text { Food } \\
\text { categories }\end{array}$ & Sample & $\mathrm{n}$ & $\mathrm{A}$ & $\mathrm{s}$ & Range \\
\hline \multirow{11}{*}{ Vegetables } & Chard & 32 & 101 & 28 & $65.5-160$ \\
\hline & Artichoke & 86 & 133 & 24 & 81.0-209.7 \\
\hline & Cauliflower & 26 & 100 & 18 & $88.1-145.5$ \\
\hline & Cabbage & 20 & 79 & 24 & $43.0-157.2$ \\
\hline & Lettuce & 313 & 101 & 22 & $43.2-149$ \\
\hline & Potato & 19 & 119 & 26 & $51.0-151.0$ \\
\hline & Pepper & 26 & 73 & 16 & $47.42-108.0$ \\
\hline & Tomato & 126 & 74 & 14 & 38.0-150.9 \\
\hline & Onion & 4 & 24 & 6 & $17-31.97$ \\
\hline & Leak & 1 & $109 \pm 4^{*}$ & - & - \\
\hline & Beans & 1 & $104 \pm 4^{*}$ & - & - \\
\hline \multirow{14}{*}{ Fruits } & Lemon & 46 & 48 & 9 & $30.0-74.0$ \\
\hline & Tangerine & 241 & 44 & 8 & $19.0-83.8$ \\
\hline & Orange & 411 & 44 & 8 & $18.0-81.24$ \\
\hline & Apricot & 28 & 82 & 15 & $50.0-115.0$ \\
\hline & Persimmon & 32 & 60 & 8 & $43.0-74.8$ \\
\hline & Plum & 79 & 56 & 14 & $23.0-95.0$ \\
\hline & Apple & 2 & 39.0 & 1.4 & $38-40$ \\
\hline & Peach & 101 & 61 & 11 & 39.0-101.9 \\
\hline & Melon & 33 & 87 & 22 & $46.1-133.3$ \\
\hline & Loquat & 27 & 47 & 9 & 20.0-63.0 \\
\hline & Pear & 26 & 43 & 9 & $23.9-56.5$ \\
\hline & Grape & 107 & 63 & 20 & 26.0-105.9 \\
\hline & Watermelon & 15 & 45 & 13 & $28.5-73.4$ \\
\hline & Pomegranate & 6 & 64 & 4 & $58.1-68.9$ \\
\hline \multirow{3}{*}{ Cereals } & Rice & 28 & 76 & 20 & 40.0-117.9 \\
\hline & Barley & 93 & 149 & 31 & $78.0-222.4$ \\
\hline & Wheat & 14 & 108 & 16 & $67.0-122.6$ \\
\hline \multirow{6}{*}{ Others } & Corn & 2 & 82 & 53 & $45-118$ \\
\hline & Sunflower & 1 & $251 \pm 8^{*}$ & - & - \\
\hline & Lentils & 2 & 198 & 30 & $177-219$ \\
\hline & Olive & 56 & 224 & 51 & $50.0-379.6$ \\
\hline & Almond & 57 & 236 & 41 & $130.0-340.0$ \\
\hline & Carob & 2 & 231 & 30 & $210-252$ \\
\hline Milk $^{\mathrm{a}}$ & $\operatorname{Milk}\left(\mathrm{Bq} \cdot \mathrm{L}^{-1}\right)$ & 85 & 42 & 10 & $17.7-72.37$ \\
\hline Fish & Fish & 9 & 90 & 36 & 58.1-158.9 \\
\hline \multirow{3}{*}{ Meat } & Lamb & 8 & 86 & 22 & $53-111.5$ \\
\hline & Rabbit & 3 & 81 & 17 & $67.2-100.9$ \\
\hline & Poultry & 5 & 78 & 35 & $22-115$ \\
\hline Eggs & Eggs & 5 & 46 & 0.7 & $41.6-49.0$ \\
\hline
\end{tabular}


It can be observed that foods with higher concentrations of ${ }^{40} \mathrm{~K}$ are almonds and olives, with values above $300 \mathrm{~Bq} \cdot \mathrm{kg}^{-1}$. Cereals (wheat, barley or rice) reach values of $224.4 \mathrm{~Bq} \cdot \mathrm{kg}^{-1}$. Citrus and fruits present values ranging from $18 \mathrm{~Bq} \cdot \mathrm{kg}^{-1}$ of oranges to $133 \mathrm{~Bq} \cdot \mathrm{kg}^{-1}$ of melon. Vegetable samples vary between low values for onion samples (17-32 Bq. $\mathrm{kg}^{-1}$ ) and values close to $200 \mathrm{~Bq} \cdot \mathrm{kg}^{-1}$ for artichokes.

Meat samples have values ranging from $22 \mathrm{~Bq} \cdot \mathrm{kg}^{-1}$ in a sample of poultry and $159 \mathrm{~Bq} \cdot \mathrm{kg}^{-1}$ in a sample of river fish. The concentration of ${ }^{40} \mathrm{~K}$ in eggs has an average value of $46.5 \mathrm{~Bq} \cdot \mathrm{kg}^{-1}$. For samples of milk (cow or goat) a mean value of 42.1 Bq.L. $\mathrm{L}^{-1}$ was obtained.

The total concentration of potassium $(\mathrm{mg} / \mathrm{g})$ calculated from the mean values of ${ }^{40} \mathrm{~K}$ and considering an abundance of $0.0118 \%$ agrees with values given in the literature for potassium in food (CRC, 2003).

In order to assess the temporal evolution of ${ }^{40} \mathrm{~K}$ content in the analyzed samples, lettuce and orange data were considered. Figure 2 shows the temporal evolution of the activity of ${ }^{40} \mathrm{~K}$ regardless of their sampling location. It is observed an increasing in the potassium concentration of about $20 \%$. This increasing is not an anomaly due to sampling, sample moisture condition or the sample preparation procedure since all samples are similarly collected and prepared. The reason may be the increasingly widespread use of fertilizers with high concentrations of potassium (Bolca, M et al, 2007; Römheld, V., Kirkby, E.A., 2010).



Figure 2. Temporal evolution of ${ }^{40} \mathrm{~K}$ activity concentration (Bq.kg $\left.{ }^{-1}\right)$.

Moreover, in order to check if any sampling site is significantly different to the rest, it has been calculated the mean value for each one with all available data for both oranges and lettuces. Figure 3 shows the results obtained for all sampling sites. Notice that no site is significantly different from the rest. 


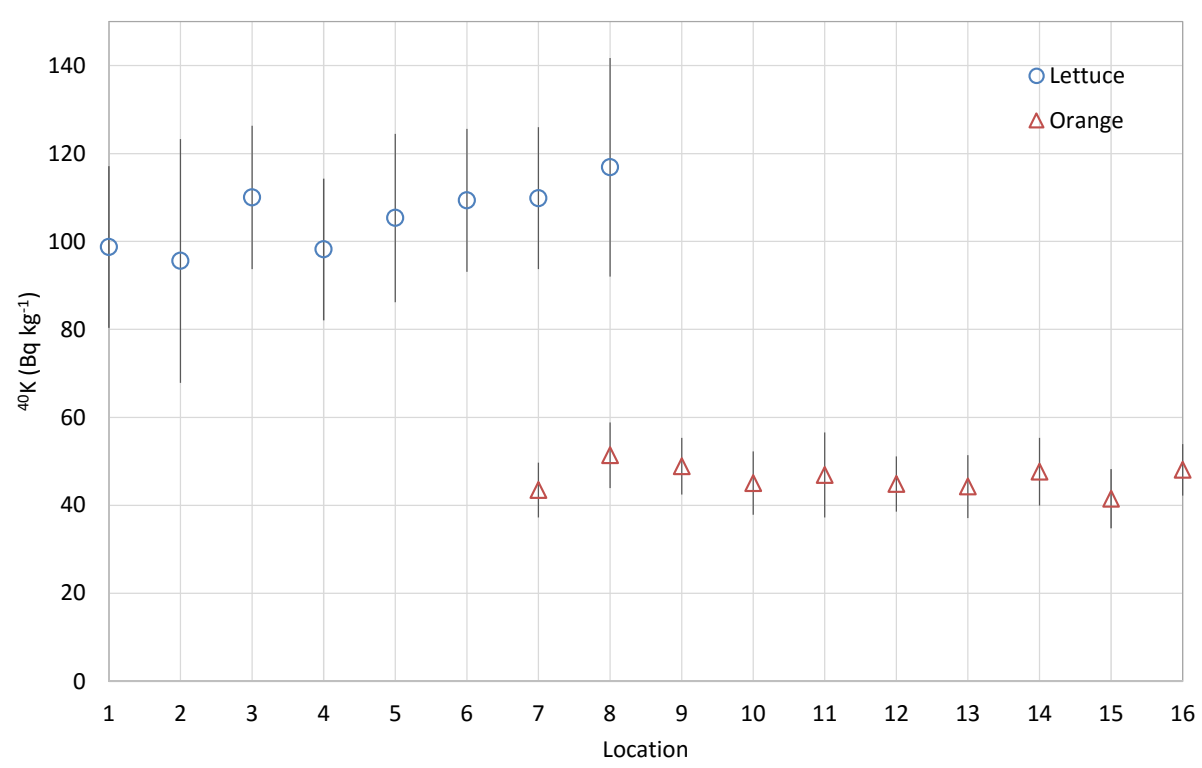

Figure 3. Activity concentration of ${ }^{40} \mathrm{~K}\left(\mathrm{~Bq} \cdot \mathrm{kg}^{-1}\right)$ in lettuce and orange.

\subsubsection{Activity concentration of ${ }^{131} \mathbf{I}$}

On March, 11th, 2011, the Fukushima NPP accident caused air pollution. The plume reached Spain on March, 22th (CSN, 2011). On March, 26th, ${ }^{131} \mathrm{I}$ was detected in air samples collected in the laboratory (LRA). For this reason, the original number of samples within the environmental monitoring program established for 2011 was extended adding new ones. A $\gamma$-ray spectrometry analysis was performed.

${ }^{131}$ I was detected in samples collected between March, $31^{\text {st }}$ and April, $6^{\text {th }}$. The values range from 0.1 to $1.5 \mathrm{~Bq} \cdot \mathrm{kg}^{-1}$. In the samples collected one month later, ${ }^{131}$ I activity was not detected. Table 3 shows the activity concentration and expanded uncertainty $(\mathrm{k}=2)$. The MDA values for each sample measured are presented.

Table 3. Activity concentration of ${ }^{131} \mathrm{I}\left(\mathrm{Bq} \cdot \mathrm{kg}^{-1}\right)$ following the Fukushima NPP accident.

\begin{tabular}{|c|c|c|c|c|}
\hline \multirow{2}{*}{ Location } & Sample & Collected date & $\mathrm{A} \pm \mathrm{U}$ & $\begin{array}{c}\text { Minimum Detected Activity } \\
\text { (MDA) }\end{array}$ \\
\hline \multirow{2}{*}{3} & Lettuce & $05 / 04 / 2011$ & & $<0.10$ \\
\cline { 2 - 5 } & Chard & $11 / 05 / 2011$ & & $<0.26$ \\
\hline \multirow{2}{*}{6} & Lettuce & $05 / 04 / 2011$ & $0.21 \pm 0.10$ & $<0.11$ \\
\cline { 2 - 5 } & Lettuce & $26 / 04 / 2011$ & & $<0.08$ \\
\cline { 2 - 5 } 7 & Lettuce & $05 / 04 / 2011$ & $0.10 \pm 0.08$ & $<0.19$ \\
\hline \multirow{2}{*}{8} & Lettuce & $11 / 05 / 2011$ & & $<0.17$ \\
\cline { 2 - 5 } & Chard & $06 / 04 / 2011$ & $1.51 \pm 0.16$ & $<0.11$ \\
\hline \multirow{2}{*}{21} & Chard & $10 / 05 / 2011$ & & $<0.17$ \\
\hline
\end{tabular}

The levels detected of ${ }^{131} \mathrm{I}$ are similar to data reported in other northern hemisphere countries (Thakur, P., 2013). In no case did the detected values exceed the established limits (Euratom, 1987a, 1989b).

\subsection{Radiochemical analysis of ${ }^{90} \mathrm{Sr}$}

The presence of ${ }^{90} \mathrm{Sr}$ in foods has its origin mainly in soils contaminated as a result of nuclear tests performed in the Northern Hemisphere in the 60s. A radiochemical separation of ${ }^{90} \mathrm{Sr}$ has been carried out in 334 samples of the 2200 samples collected. Of them, almost $96 \%$ present activity 
concentration of ${ }^{90} \mathrm{Sr}$. Table 4 shows the average value of activity concentration of ${ }^{90} \mathrm{Sr}$ in samples with values over MDA values (A), the standard deviation (s) and the range of values.

Table 4. Activity concentration of ${ }^{90} \mathrm{Sr}\left(\mathrm{Bq} \cdot \mathrm{kg}^{-1}\right)$ in foodstuffs

\begin{tabular}{|c|c|c|c|c|c|}
\hline $\begin{array}{c}\text { Food } \\
\text { categories }\end{array}$ & Sample & $\mathrm{d} / \mathrm{a}^{\mathrm{a}}$ & A & $\mathrm{s}$ & Range \\
\hline \multirow{8}{*}{ Vegetables } & Chard & $2 / 2$ & 0.0605 & 0.049 & $0.026-0.095$ \\
\hline & Cauliflower & $1 / 1$ & $0.019 \pm 0.004^{*}$ & & - \\
\hline & Cabbage & $2 / 2$ & 0.016 & 0.014 & $0.0059-0.025$ \\
\hline & Lettuce & $146 / 146$ & 0.025 & 0.023 & $0.011-0.162$ \\
\hline & Potato & $3 / 4$ & 0.023 & 0.019 & $0.0034-0.042$ \\
\hline & Tomato & $3 / 4$ & 0.012 & 0.007 & $0.006-0.019$ \\
\hline & Onion & $2 / 2$ & 0.012 & 0.008 & $0.006-0.018$ \\
\hline & Leak & $1 / 1$ & $0.047 \pm 0.007^{*}$ & & - \\
\hline \multirow{8}{*}{ Fruits } & Lemon & $2 / 2$ & 0.025 & 0.001 & $0.024-0.025$ \\
\hline & Tangerine & $10 / 11$ & 0.016 & 0.017 & $0.0034-0.062$ \\
\hline & Orange & $82 / 82$ & 0.021 & 0.015 & $0.0034-0.094$ \\
\hline & Apricot & $1 / 1$ & $0.041 \pm 0.009 *$ & & - \\
\hline & Loquat & $1 / 3$ & $0.031 \pm 0.013^{*}$ & & - \\
\hline & Peach & $1 / 3$ & $0.038 \pm 0.010^{*}$ & & - \\
\hline & Melon & $3 / 3$ & 0.016 & 0.006 & $0.013-0.023$ \\
\hline & Grape & $10 / 10$ & 0.037 & 0.024 & $0.013-0.094$ \\
\hline \multirow{3}{*}{ Cereals } & Barley & $3 / 3$ & 0.34 & 0.13 & $0.201-0.44$ \\
\hline & Wheat & $9 / 9$ & 0.48 & 0.28 & $0-13-1.04$ \\
\hline & Corn & $1 / 1$ & $0.070 \pm 0.069^{*}$ & & - \\
\hline \multirow{5}{*}{ Others } & Sunflower & $1 / 1$ & $0.5 \pm 0.3^{*}$ & & - \\
\hline & Lentils & $1 / 1$ & $0.22 \pm 0.03^{*}$ & & - \\
\hline & Olive & $5 / 5$ & 0.21 & 0.17 & $0.026-0.43$ \\
\hline & Almond & $7 / 7$ & 0.40 & 0.21 & $0.16-0.84$ \\
\hline & Carob & $2 / 2$ & 0.180 & 0.028 & $0.16-0.2$ \\
\hline Milk & Milk $^{b}$ & $19 / 19$ & 0.04 & 0.02 & $0.016-0.089$ \\
\hline Eggs & Eggs & $1 / 1$ & $0.063 \pm 0.013^{*}$ & & - \\
\hline
\end{tabular}

According to Table 4, the highest values correspond to samples of cereals, almonds and olives, with mean values of $0.20 \mathrm{~Bq} \cdot \mathrm{kg}^{-1}$ for olives, $0.40 \mathrm{~Bq} \cdot \mathrm{kg}^{-1}$ for almonds and $0.48 \mathrm{~Bq} \cdot \mathrm{kg}^{-1}$ for wheat, which is one order of magnitude above the rest of the samples. Most foodstuffs have lower mean values than $0.1 \mathrm{~Bq} \cdot \mathrm{kg}^{-1}$.

The determination of ${ }^{90} \mathrm{Sr}$ has been carried out in 146 lettuce and 82 orange samples. Activity concentration range from $11 \mathrm{mBq} \cdot \mathrm{kg}^{-1}$ to $162 \mathrm{mBq} \cdot \mathrm{kg}^{-1}$ for lettuce and from $3.4 \mathrm{mBq} \cdot \mathrm{kg}^{-1}$ to 93.5 $\mathrm{mBq} \cdot \mathrm{kg}^{-1}$ for oranges. Figure 4 shows the temporal evolution of the activity for lettuce and orange samples. A slight decreasing is observed from the 90 s to the present days. 




Figure 4. Temporal evolution of ${ }^{90} \mathrm{Sr}$ activity concentration (Bq. $\left.\mathrm{kg}^{-1}\right)$

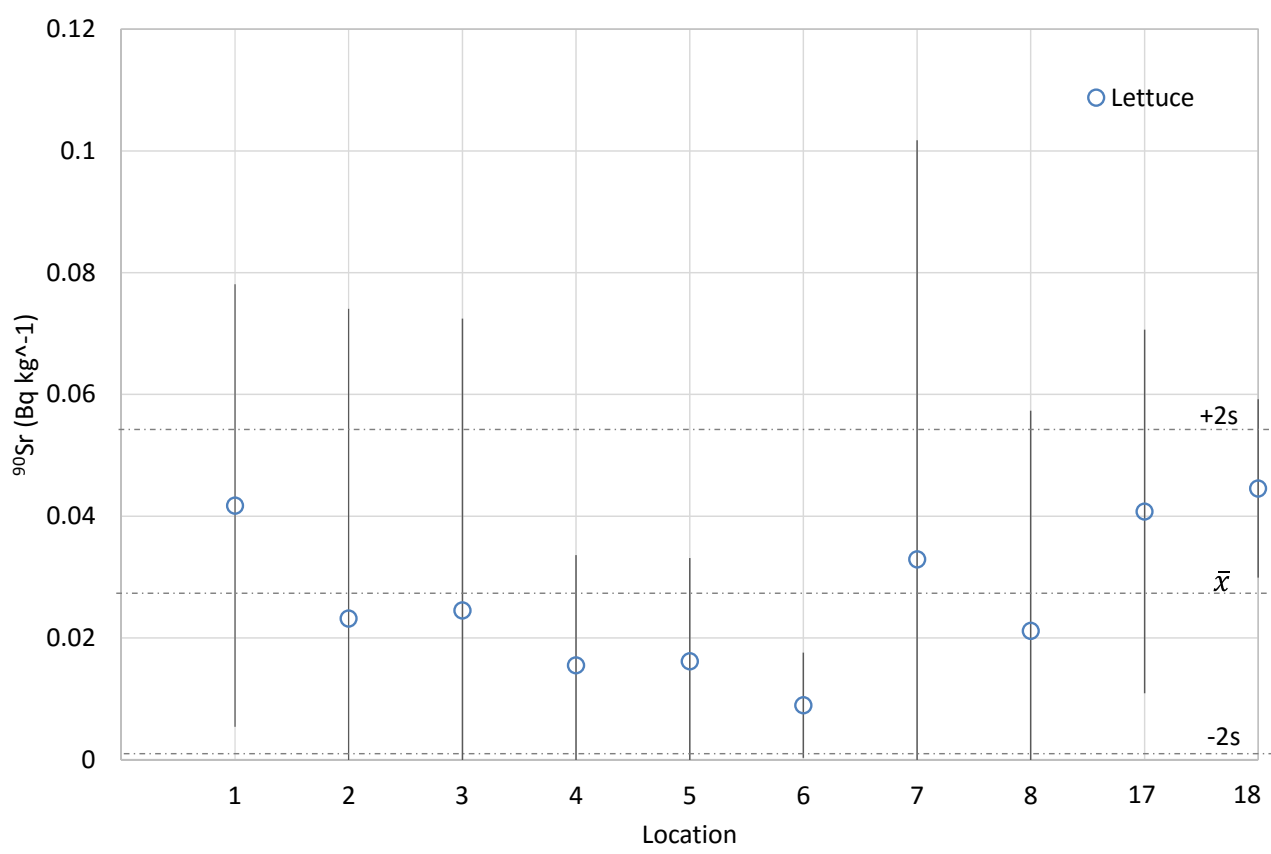

Figure 5. Activity concentration of ${ }^{90} \mathrm{Sr}\left(\mathrm{Bq} \cdot \mathrm{kg}^{-1}\right)$ for lettuce samples. 


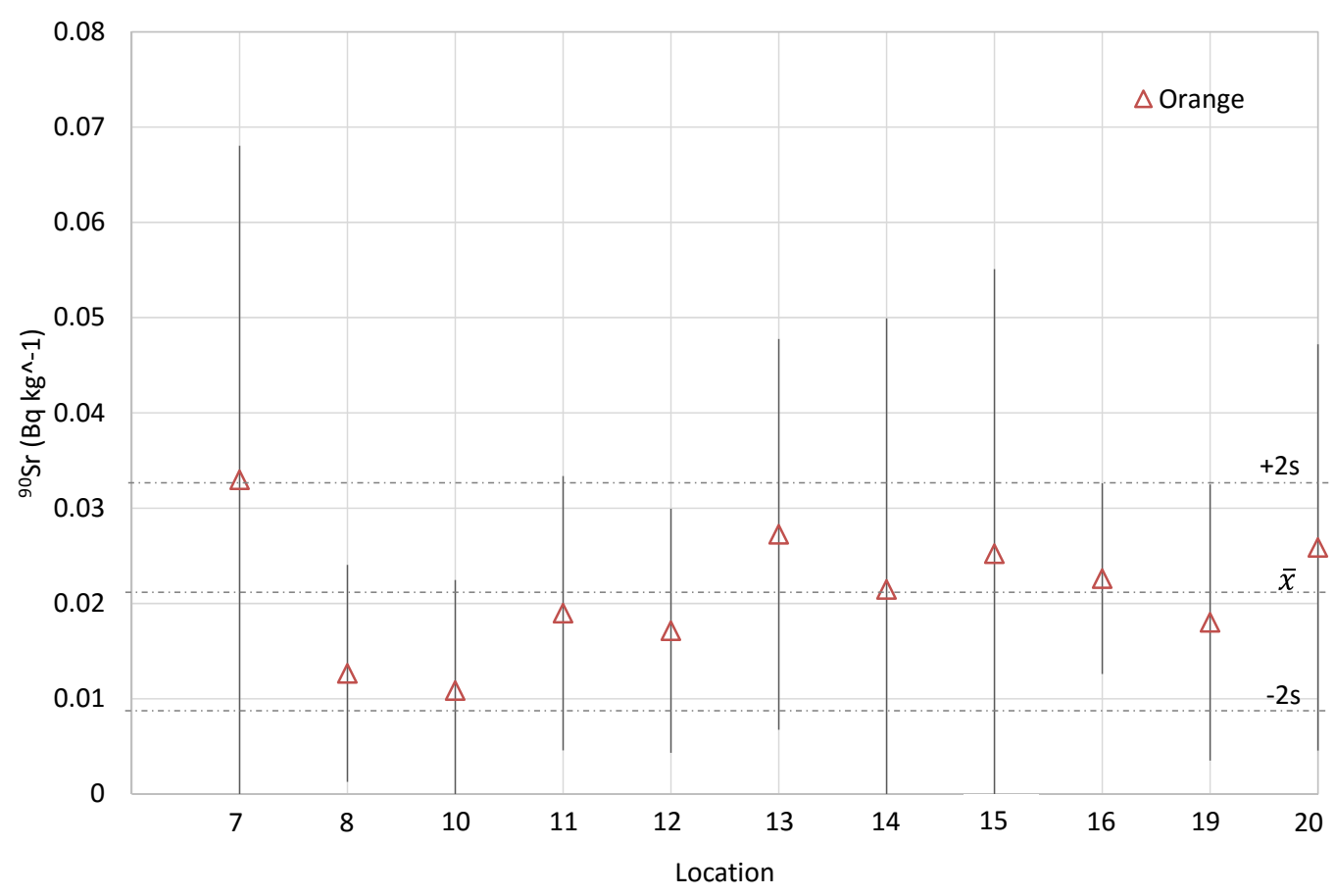

Figure 6. Activity concentration of ${ }^{90} \mathrm{Sr}\left(\mathrm{Bq} \cdot \mathrm{kg}^{-1}\right)$ for orange samples.

To assess whether there is a site at which the concentration of ${ }^{90} \mathrm{Sr}$ is significantly different from the others, the mean value for each site has been plotted for both lettuce and orange and compared with the average value of all samples. Figure 5 and Figure 6 show the results obtained for each sampling location. It is observed that all points are within the confidence interval of the overall average value. No point is significantly different from the others. In no case did the activity concentration of ${ }^{90} \mathrm{Sr}$ exceed established limits (Euratom 1987a, 1989b).

\section{Conclusions}

In this work has been shown that radioactivity levels are monitored in foodstuffs in Comunidad Valenciana. Analyses of representative foods are carried out during the year.

A total of 2200 samples have been collected between 1991 and 2013. Gamma-ray spectrometry analysis of samples confirmed the presence of ${ }^{40} \mathrm{~K}$ in all samples collected. The values correspond to that expected when related to the concentration of total potassium in the same samples. In some samples of vegetables such as chard, cabbage and lettuce with large area of deposition, in fruits such as grapes and apricots consumed unpeeled and unhusked grains ${ }^{7} \mathrm{Be}$ was detected. ${ }^{90} \mathrm{Sr}$ has been detected in concentrations below $1 \mathrm{~Bq} \cdot \mathrm{kg}^{-1}$, at levels consistent with post atmospheric testing from the 1960s.

In the analyzed samples collected some days following the Fukushima NPP accident ${ }^{131}$ I was detected. The activity concentration of ${ }^{131}$ I has decreased to values below the MDA in samples collected some days after the first sampling.

Activity concentration values of ${ }^{90} \mathrm{Sr}$ and ${ }^{131}$ I detected are all well below the maximum permitted levels of radioactivity for foodstuffs listed in the EURATOM Regulation No. 2218/89 of the Council of the EU. 


\section{Acknowledgements}

The authors thank the Conselleria de Agricultura, Pesca y Alimentación and the Conselleria de Interior $y$ Justicia of the Generalitat Valenciana for the financial support of the projects over the period 1991-2013 in which we have analyzed the samples studied for this work.

\section{References}

Abukawa J., Tsubuku C., Hayano K., Hirano, K., 1998. A survey of ${ }^{90} \mathrm{Sr}$ and ${ }^{137} \mathrm{Cs}$ Activity levels of retail Foods in Japan. J. Environ. Radioactivity, Vol. 41, 3, 287-305.

Akhter, P., Orbi, S.D., Ahmad, N., 2003. Caesium concentration in the Pakistani diet. J. Environ. Radiactivity, 67, 109-118.

Arogunjo, A.M., Ofuga, E.E., Afolabi, M.A., 2005, Levels of natural radionuclides in some Nigerian cereals and tubers., J. Environ. Radioactivity 82, 1-6.

Beresford, N.A., et al., 2012. Observations of Fukushima fallout in Great Britain. J. Environ. Radioactivity, 114, 48-53.

Bolca, M., Saç, M.M., Çokuysal, B., Karah, T., Ekdal, E., 2007. Radioactivity in soils and various foodstuffs from the Gediz River Basin of Turkey. Radiation Measurements, 42, 263-270.

Choi, M-S., et al. 2008. Daily intakes of naturally occurring radioisotopes in typical Korean foods. J. Environ. Radiactivity, 99, 1319-1323.

Council regulation (EURATOM) No 3954/87, Council of the European Communities, 1989.

Council regulation (EURATOM) No 2218/89, Council of the European Communities, 1989.

CRC Handbook of Chemistry and Physics, 2003.

CSN, 2011. Seguimiento del Accidente nuclear de Fukushima. Vigilancia Radiológica Ambiental en España. http://www.csn.es/index.php/es/especiales/accidente-en-fukushima-japon/vigilanciaradiologica-ambiental-en-espana

Esposito M., et al., 2002. Survey of natural and anthropogenic radioactivity in environmental simples from Yugoslavia. J. Environ. Radioactivity, 61, 271-282.

Froidevaux, P., Geering, J.J., Pillonel, L., Bosset, J.O., Valley, J.F., 2004. ${ }^{90} \mathrm{Sr},{ }^{238} \mathrm{U},{ }^{234} \mathrm{U},{ }^{137} \mathrm{Cs},{ }^{40} \mathrm{~K}$ and ${ }^{239 / 240} \mathrm{Pu}$ in Emmental type cheese produced in different regions of Western Europe. J. Environ. Radioactivity, 72, 287-298.

Huang-Sheng Chiu, et al., 2013. Radioactivity inspection of Taiwan For food products imported from Japan after the Fukushima nuclear accident. Applied Radiation and isotopes, 81, 356-357.

IAEA, Measurements of radionuclides in food and the environment. A guidebook, Vienna 1989. Technical Report, series no 295.

ICRP Publication 20. Alkaline Earth Metabolism in Adult Man, 1973.

Mahiban Ross, E., Lenin Y., Godwin W, S., Rajan, M.P., 2013. Selected natural and fallout radionuclides in plant foods around the Kudankulam Nuclear Power Project, India. J. Environ. Radioactivity, 115, 201-206.

Römheld, V., Kirkby, E.A., 2010. Research on potassium in agriculture: needs and prospects. Plant Soil, 335, 155-180.

Shanthi, G., Thampi, J., Allan, G. Maniyan, C.G., 2010. Natural radionuclides in the South Indian foods and their annual dose. Nuclear Instruments and Methods in Physics Research A, 619, 436440 .

Thakur, P., Ballard, S., Nelson, R., 2013. An overview of Fukushima radionuclides measured in the northern hemisphere. Science of the Total Environment, 458-460, 577-613.

UNE 34117, 1981, Frutas y verduras frescas. Muestreo. 
U.S. Environmental Protection Agency, 1984, Radiochemistry Procedures Manual (EPA 520/5-84006) Montgomery, AL. 